\title{
Impact of Strategic Ambiguity Tagline on Billboard Advertising on Consumers Attention
}

\author{
Chimeziem E. Nwankwo-Ojionu ${ }^{1 *}$ \\ (iD) 0000-0002-8058-7707
}

Nor Azura Adzharuddin ${ }^{1}$

(D) 0000-0002-4924-1054 SC 57189506578

Moniza Waheed ${ }^{1}$

(iD) 0000-0002-4470-1381 SC 55744428500

\author{
Azlina Mohd Khir ${ }^{1}$ \\ (iD 0000-0001-8398-7653 \\ ${ }^{1}$ University Putra Malaysia, MALAYSIA \\ *Corresponding author: cenochi113@gmail.com
}

Citation: Nwankwo-Ojiou, C. E., Adzharuddin, N. A., Waheed, M., \& Mohd Khir, A. (2022). Impact of Strategic Ambiguity Tagline on Billboard Advertising on Consumers Attention. Online Journal of Communication and Media Technologies, 12(1), e202204. https://doi.org/10.30935/ojcmt/11432

ARTICLE INFO

Received: 23 Jun 2021

Accepted: 04 Dec 2021

\begin{abstract}
Using strategic ambiguity tagline paradigm, we demonstrated that the strategic ambiguity tagline influences consumer attention on billboard advertisement evaluation. Despite the exceptional influence of strategic ambiguity tagline on billboard advertisement evaluation, the concept of strategic ambiguity tagline as discursive resources remains poorly conceptualised by previous studies. An experimental study was conducted to investigate the underlying mechanisms and circumstances that influence the impact of strategic ambiguity tagline on consumers attention. Findings revealed that strategic ambiguity tagline has a significant influence on consumers attention. However, we further observed strong effects of attitude towards tagline ads, perception towards tagline ads and brand motives using tagline ads on consumer attention when exposed to the ads, which signify effectiveness of strategic ambiguity tagline on consumer's attention. The theoretical and managerial implication are discussed.
\end{abstract}

Keywords: billboards advertising, consumers attention, multiple interpretation strategic ambiguity, tagline

\section{INTRODUCTION}

The strategic ambiguity tagline usage has become progressively prominent in billboard adverting recently. Billboard advertising is a type of outdoor advertising employed by businesses in open spaces with heavy traffic, where they are visible to passing pedestrians and motorist. The visibility of billboard advertisement to so many market groups are believed to have a communicative influence on customers and position that is very dissimilar from other advertising media because it offers the utmost challenge in "marketing communication" (Everlin \& Erlyana, 2020; Schirm, 2010; Zekiri, 2019). Companies and practitioners deliberately use ambiguous taglines to pique interest of consumers and to present multiple interpretations, which allows for a steady shift that is implicitly expressed in order to preserve flexibility, define measurable goals, and brand identity towards achieving multiple goals across various individuals to apprehend consumer's attention, brand liking, patronage and loyalty (Pietsch, 2021; Schäfer, 2020). Yet this phenomenon has not been studied extensively, irrespective of its importance in the marketing communication process of organisation. However, organisation and its operative's uses taglines, symbols and codes purposefully to achieve multiple interpretation because they influence communication process towards accomplishing 
multiple goals. Seemingly, the taglines, symbols and logos are encoded in high levels of abstraction that might not be clear to all just before a more demanding "conceptualization" of how things are done. Strategic ambiguity raises the presence of multiple standpoints in communication and the use of ambiguity can be traced to advertising, mission statement, goals, and plans (Aggerholm et al., 2012; Fløttum, 2010; Hoffjann, 2021). Strategic ambiguity is fundamental towards creating impactful tagline for strategic reasons to communicate because it permits "multiple interpretations" to happen amongst individual that struggle to respond to the same message, perceived to be clear (Eisenberg, 1984; Sumelius et al., 2020).

Generally, the theoretical framework presented here towards examining the impact of strategic ambiguity tagline in billboard advertisement is underpinned on strategic ambiguity approach for accomplishing organisational goals. The study begins with a literature review on reminiscent of the fundamental concepts of the strategic ambiguity perspectives and how it is linked to tagline followed by conceptual background, impact of strategic ambiguity tagline in advertisement. The study presented a detailed procedure of the experiment whereby the randomised participants were presented with different billboards ads tagline, the findings from the experimental procedure were presented, and the study implications were discussed at the end.

\section{STRATEGIC AMBIGUITY}

Remarkably, Stacho et al. (2019) highlighted that open communication, as a tool for successful communication and consumer engagement, which epitomized clarity message spread or utilizing a transactional model that typified the formation of collective meanings. However, simplicity is an acknowledged measurement of effective communication, and are critical for building high-level knowledge and beliefs among individuals and motivating them to grasp the principles and virtues expected in any given brand message (Rolin \& Karahan, 2020). In contrast, Cappelen and Strandgaard (2021) posits that ambiguity is purposefully utilised to encourage agreement on abstractions while without restricting specific interpretations, which enhances the ability to attain goals and serves for purposes towards promotion of unified diversity, preserves privilege positions, deniable and facilitate organisational change (Cappelen \& Pedersen, 2021).

The advertising primes a context to accomplish with certain extent of ambiguity in the communication process because consumers no longer consider lexical ambiguity to be a bad language feature, but instead aim to use it creatively (Zhou, 2021). However, strategic ambiguity takes place when an anticipated advertisement message (taglines) the connotation is unclear conveyed to a recipient. This viewpoint is considered by the strategic and purposefulness utilization of messages with higher "levels of abstraction" to instantaneously achieve multiple, and frequently contradictory, "organizational goals". Deliberately "ambiguous messages" are created to stimulate dissimilar interpretations of the same set of" symbols" within and across diverse audience (Eisenberg, 1984; Martin \& Pajouh, 2019; Wright, 2019).

Meanwhile, the complexity of the connotation is a difficulty in meaning utilised in an advertisement channelled to the consumers in the message structure about the brand and its benefits that facilitate apprehending the attention of consumers (Juliana \& Arafah, 2018). Ideally, ambiguity has been consistently used for effectiveness of persuasion, mostly characterised as strategic ambiguity (Han \& Hong-Lim, 2015). Individuals infers meaning to a context that is not in-built in the dialogue. If an advertisement tagline is perceived to be ambiguous or unambiguous it is contingent on the "contextual dimension". Invariably, clarity and ambiguity is relational in nature that arises from the "source, message and receiver" influence (Johansen, 2018). However, the intentional violation of language norms, laws of linguistic conduct, and cliches of language in order to add greater expressive force to advertising content such as advertising texts, slogans, and advertising names is defined as language games in it ambiguous perspective (Teletova \& Letunovska, 2019).

Past studies highlighted how strategic ambiguity are used to achieve multiple interpretation and multiple goals for the organisation such as Nasr (2020) discovered firstly that, voters use a 'likability' heuristic, in which they view the party they (dis)like as being closer to (far from) their stance, independent of the party's real position. Second, as the voter's uncertainty grows, so does the likability impact. When confronted with an unclear party, voters who dislike the party overstate the ideological difference, and those who like the party underestimate it. These findings imply that ambiguity may benefit the party to the degree that it is loved, but 
it may backfire if the party is not popular enough. In another study Botti and Monda (2019) found that uncertainties evolved about three areas of goal ambiguity: measuring methodologies, variables that impact and are influenced by goal ambiguity, and the link between goal ambiguity and organisational performance. In a similar study Oryila and Umar (2016) examined "vagueness and ambiguity" in print media advertisements used to promote ideas, products and services". The outcome indicated that vagueness and ambiguity are used in lack of knowledge, in error, by chance or purposefully in advertisements. Mainly to misinform, to complicate, to entertain, to evade truth, to persuade, and to make certain ideas, products and services appear plausible or more plausible than they really are in defiance to the prevailing ideology of clarity and openness in public. Meanwhile, Winstock et al. (2020) study found that the fact of drinking less can lessen the risk of seven forms of cancer was the least commonly known, yet it was shown to inspire almost $40 \%$ of drinkers to consider drinking less. Women and high-risk drinkers were more likely to say they would cut back on alcohol in response to all labels. Personal relevance was discovered to be a significant predictor of individual responses. The findings indicate the potential for a variety of health messages presented on alcoholic beverages to enhance awareness of alcohol-related harms and maybe assist a decrease in consumption.

In view of the previous study's findings, in conjunction that little is known specifically on the impact of strategic ambiguity tagline in billboard advertisement, and how consumer's attention is influenced, additional study is needed to uncover the impact of strategic ambiguity tagline in billboard, which will be useful to advertisers, companies, practitioners and policymakers. Ideally, strategic ambiguity tagline rhetorical devices are an important aspect of billboard advertisement that has been used extensively to apprehend consumer's attention to the brand recall, recognition and favourable attitude to the brand, which makes it an essential concept to study. This will be achieved through the constructs found in Song and Luximon (2019) attitude towards tagline (lettering case, typeface), Henderson et al. (2004) perception towards tagline, Smith et al. (2006) brand motives using tagline as fundamental elements that will facilitate understanding the impact of strategic ambiguity tagline in billboard.

The purpose of this study is to examine impact of strategic ambiguity tagline in billboards advertising. Specifically, the study aims to examine whether the attitude and perception of consumers exposed to strategic ambiguity tagline differ in attention from those that were unexposed and to examine if brand motives in using strategic ambiguity tagline influence consumers' attention towards achieving multiple marketing communication goals of the organisation as discursive resources of communication. However, tagline is organisation catchphrase and mantra (repeated words or sound) in all their communication process. The strategic ambiguity taglines invoke various interpretation tendencies because of the linguistic devices applied to taglines such as metaphor, polysemy, semantic that comes in its lexical and syntactic structures conveying brand offerings and positioning in the market place (Baranova \& Blyzniuk, 2019).

\section{CONCEPTUAL BACKGROUND}

\section{Tagline}

Language is fundamental tool in human communication that offers devices of influencing favourable behaviour when it is efficiently used, taglines has the capacity of conveying the "personality of a brand and its unique position in the marketplace" (Dirwan et al., 2021; Shahid \& Ashfaq, 2021). Accordingly, Munthe and Lestari (2016) stated that taglines are devices used in capturing the audiences' attentions through wordplay, phrases, or sentences and rhetorical devices and a decent tagline stimulates audiences' attentions and expressions of the message relevance and connation and connections and attracts patronage to the brand. Remarkably, the most successful ads ever seen are deeply rooted in linguistic devices, which enable them to successfully draw attention to the brand, and sustains the consumers over time. Brand taglines are open for multiple interpretation among consumers and become fundamental topic for discussion, either in favour or not (Do \& Polsa, 2018). Similarly, the taglines operate to explicate brand and its activities, what they are offering and encourage consumers to patronise. For example, "finger licking", "if it is not Panadol it is not the same thing as Panadol", "everyone can fly", "Life is good". Tagline uses linguistic devices of any geographical location without restrictions to engage consumers on the product and services of the company (Tur \& Pratishara, 2018). Accordingly, Syahruddin and Karim (2019) highlighted that tagline is a lesser "sentence" presented as the ending "text of the fundamental that accomplishes briefly the resolve of communication of 
an advertisement. Taglines are utilised assist communicating the peculiarity standpoint of competitors. Most advertisements use attractive taglines that enables the "brands to get more potential buyers". The more distinctiveness the linguistic the more eye-catching the tagline will be (Baharudin, 2015).

Meanwhile, Miller and Toman (2015) mentioned that taglines does not convey a direct meaning and may be subject to multiple interpretations, which can be measured in two forms, lexical and syntactic. The lexical is the length of words in the phrase or slogan, while syntactic is the organisation and the procedure of parts of speech, which includes modifiers. It requires careful consideration and interpretation. This is because slogans do not accommodate so many words, rather the contain short words that are salient to the product or brand. "The difference is clear" which is vague or lacks clue to the meaning. According to Richard-Bollans et al. (2020), expressions with numerous meanings are denoted to be "polysemy" and are commonly used in brand tagline. For example, Air Asia's "everyone can fly", Proton's "It's in the Drive", Perodua's "Building Cars people first". The taglines cue associates with the brands, which convey essential standpoint of the brand to consumers with primed devices that establishes the brand in the memory of the consumers.

\section{Perception towards tagline}

There is a notion that a congruent advertisement draws less attention as perceived by so many consumers (Mantonakis, 2012). However, perception determines how we see an object or feel about sets of stimulus in ads. According to Chatterjee (2019), Cheema et al. (2016) "perception is all about the experience that is held by the customer". Consumers perception determines the decision they make about a brand or an advertisement, which is contingent on long held experience with the brand over time through interaction, awareness, recall and positioning (Jun \& Lee, 2007; Thapa, 2021). While, Gupta et al. (2020) suggested that awareness is the most noticeable pointer is recall, which is ability of the consumers to remember the tagline or brand associated with the tagline (Wang, 2010)

Advertisements strategically creates or encodes a pause in between tagline and target words. This approach creates ambiguity or discrepancy on the perceived words of tagline that invokes a cognitive processing of the wordings towards decoding what this pause or insufficiency on the target words. Moreover, Kronlund and Whittlesea (2006) study on "remembering after a perception of discrepancy: out with the old, in with the two". The study was a recognition test to ascertain if "perception" also influence memory activity when it is" experienced in the original encounter with a stimulus". The study indicated that perception of discrepancy in the first encounter is likely to facilitate later "recognition but can also facilitate "systematic memory errors under some circumstances". However, the study revealed that the "perception of discrepancy also serves an alerting function, drawing increased attention to the stimulus" that enable the individual to engage in thoughtful process and developing attention to the context.

Conversely, tagline investigation and its ambiguity borders on linguistic and structural nature without much thought on the colour aspect of tagline. Marketers and companies has used colour to influence perception and purchase behaviour of consumers. Accordingly, Gupta et al. (2020) study discovered that Horlicks has the most popular tagline, which is "Taller Stronger Sharper," while Amul has the second most popular tagline, which is "The Taste of India." The tagline of Boost is also popular. However, the taglines of Complan and Pediasure are not as well. This means that both Complan and Pediasure have the potential to increase their sales and popularity by focusing more on changing their taglines. Meanwhile, Labrecque and Milne (2012) study revealed the importance of distinguishing the influence of colour in developing "consumer brand perceptions". In addition, colour has come to be an effective device to enable shaping "brand perceptions" and the saturation and value use in strategic ambiguity tagline to alter brand personality and purchase intent. Colour is an essential element that captures attention of audience and keep them calm to the brand activities (Singh, 2006).

\section{Brand motive using taglines}

The advertisers have goals that orchestrates the creation and usage of taglines, it is not a normal ritual or fruitless exercise rather it is intended to arouse, apprehend and achieve multiple purposes for the organisation. Accordingly, Asako (2019) suggested that strategic ambiguity elucidate the framework of the sender's motives, message content and individual metamorphoses. While, Boxman-Shabtai (2020) argues that the message source, or advertiser, purposed for a multiple interpretations of a message. In addition, 
messages are inbuilt with high levels of "abstraction" that can harvest multiple interpretations across multiple recipient. Similarly, Penta (2018) indicated that Nike's "Just do it" tagline is fascinating strategy to inspire professionals and upcoming young athletes to be successful in their career. However, Nike is ostensibly concerned with apprehending the attention of prominent fans, "increasing sales", and highlighting to the entire world the actual users of Nike Merchandise that will be seen as growing strength of the brand. In addition, Nike want to maintain the social media presence through it tagline campaign, which increases and promote Nike's merchandise sales.

Previous studies have shown how advertiser and companies utilised various mechanisms to sustain their brand including suitable language in the advertisements. However, Sundar and Cao (2020) study demonstrated that politeness used in advertisements as "well as consumers' individual differences in BJW affect judgments and attitudes toward brands". The study concluded that "individuals with a low just world belief" are more likely to nurture undesirable attitudes towards a brand with morally unclear commercial operations when language utilised in advertisement is unbiased (politer) compared if the language employed in advertisement is biased (less polite). Meanwhile, Zehra and Minton (2019) study investigated if organisation and advertisers should use religious cues and compared perception of Christianity and Islam. In addition, they examine "cue measures, businesses' motives for using cues, consumer affect, and brand evaluations". However, the study indicated that advertiser's motives using religious cue such as taglines were mainly trying to influence a precise target group of consumers and facilitating the spread and shared respect to "God".

\section{Consumer attitude towards taglines}

Consumers attitude to tagline is associated with the experience the consumer has with brand over a long period that can be traced from prior experiences about the brand, communications with the customers (brand connections), brand awareness, brand recall and brand positioning. Ideally, attitude is a "proximal determinant" of the comprehension, liking and association with the brand tagline (Khaola et al., 2014). Accordingly, Cranor et al. (2020) study discovered that regardless of the image with which these taglines were matched, the findings show that the CCPA taglines were more successful in expressing the expectation of options linked to the selling of personal information. It is vital to remember that a shorter tagline may perform better across various websites and situations, such as mobile applications and browsers. We discovered that "Don't Sell My Info" performed similarly to the two taglines now in the rules in terms of establishing an expectation of "don't sell" options. However, cutting the tagline to "Do Not Sell" and "Don't Sell" proved problematic, since these taglines did not prompt participants to consider the sale of their personal information because they did not include the phrase "my info." In a similar study, Small et al. (2007) investigated the "cultural differences in brand designs and tagline appeals". Exploring cross-cultural differences in corporate visual identity between United States and Korea. The sample were 100 top companies brand logo and taglines in each country. The outcome indicated that Korean brands are more dispersed compared to United States brands. In addition, Korean brand tagline encompasses extra values content compared to USA. Similarly, in the work of Nayeem et al. (2019) on "brand experience and brand attitude: examining a credibility-based mechanism". The aim is to examine the interaction of "brand experience and brand attitude and its influence on brand attitude", a sample of $(\mathrm{N}=405)$ automobile users. The authors indicated, "Brand experience (brand tagline) apprehends the very core of branding a lot more successfully compared to other brand ideas like "brand equity and brand associations". The study concluded that brand credibility mediated fully and highlighted "brand credibility" as a fundamental "mechanism" through which the influence of "brand experience on brand attitude" occurs.

Meanwhile, Ishchuk and Svirhun (2020) study suggested that the following language qualities of the investigated advertising tagline are the most common: imperative sentences, rhythm, ellipsis, personification, assonance, and metaphor. The findings showed that syntactic and lexical devices (39\%) dominate in the creation of effective commercial advertising slogans, followed by phonological strategies (35\%), and semantic figures of speech (26\%). In a similar study Mantonakis (2012) study demonstrated how a "brief pause between a tagline and brand increase brand name recognition and preference". The experiment showed how encoding priming through a temporary delay or pause in between the meaningful stimulus like tagline and brand name could increase brand name recognition. The study revealed a novel way to facilitate acknowledgement of brand names in contrast to formal arrangement effect of increasing attention that is detailed in fluency 
processing of the target cues. In addition, advocate that the ideal arrangement process for "brands with taglines" is the use of a "pause between the tagline and the brand". The taglines are utilised as a major marketing communication tool that communicates the proposition, which facilitate in reinforcing consumer memory and attention to the brand. Meanwhile, Heberle and Gierl (2020) study evaluated two forms of incompleteness to see if customers understood why they were being utilised (1. incompleteness that emphasises the ad message to increase consumer agreement to this message and 2 . incompleteness that induces feelings of humour). We discovered that incompleteness boosted sentiments toward well-known brands for these groups.

The brands are acknowledged as the fundamental device that enables engagement with clients (buyer and seller) towards the creation or establishing long-lasting relationship (Boush, 2013). This connection is orchestrated by fundamentals of the brand liking, brand knowledge, brand experience, and connotation of the brand offerings, which facilitate the creation of a relationship with consumers (Mykola et al., 2020). Accordingly, Suseno and Hidayat (2021) study showed that the local pride campaign, which is impacted by the practise of cross-industry collaboration with influencers, is capable of building brand personality for local shoe goods in the direction of consumer purchasing interest. The level of consumer ethnocentrism in the community creates brand awareness, which has a significant impact on purchasing decisions for local shoe products; this is also consistent with government policy through restrictions on imported commodities for products or goods that can be made domestically. In another study (Septianto et al., 2020), experimental results show that only for a destination with a less positive country-of-origin image would the match (vs. mismatch) between the country-based emotion and the emotional appeal of the product marketing boost the product's purchase likelihood. Supphellen and Nygaardsvik (2002) study on the suggested model could be a beneficial tool towards the evaluation of the prospective "country slogans", and to create "brand awareness and brand image". However, taglines facilitate humanizing the image of a brand in a strategic way towards building a lasting impression in the mind of consumers through thoughtful utilization of linguistic devices in the brand tagline.

\section{Consumers' attention}

Consumers select and devote their time, energy, and attention to multiple executed advertisement that appeals to their visual needs based on features of selective visual attention, thus top-down selection and bottom-up selection, recognition and combination of stimulus in the ads, as highlighted by the theory of visual attention (Bundesen, 1990; Jouttijärvi, 2019). Accordingly, Kyllingsbaek (2006) studies developed a model to fit into Bundesen (1990) theory of visual attention, which is a computational formula. The study revealed that its model is user friendly and flexible toward the TVA. In addition, components in the visual are parallel processed, matching check of the visual objects within the long-term memory and race selection and recognition of the visual objects to the short-term memory. Visual object competes for selection and the speed for its selection can be based on the favoured selection that is automatic "bottom-up" or intentional "top-down". Meanwhile, Reimer and Schubert (2020) experimented on "visual and central attention share a capacity limitation when the demands for serial item selection in visual search are high". In combination quest, visual attention is prerequisite to pick the "items" and to muddle its structures such as colour, form, size that occurs in a "serial search process". The study provides evidence that visual and central attention share a common capacity limitation when conjunction search relies strongly on serial item selection. Additionally, Lu et al. (2018) study offered a unique model based on Visual Attention that not only gives a greater visual comprehension of the model's judgments, but also greatly outperforms previous state-of-the-art baseline techniques for this job. In another study, Wang et al. (2020) study evaluated their proposed model on the most popular benchmark datasets. We report an improvement of 3.9\% over existing state-of-the-art approaches for cross-lingual image captioning on the Flickr8k CN dataset on CIDEr metric. The experimental results demonstrate the effectiveness of our attention model. Schubert et al. (2015) argue that the selection of the objects is similar to the encoding of the visual into the short-term memory.

Remarkably, consumer attention is one of the fundamental factors towards execution and processing brand messages on billboards advertising. These have been investigated by previous studies such as (Chopra, 2017; Hiranuma et al., 2017; Hussain \& Nizamani, 2011; Khan et al., 2016; Patel \& Bhatt, 2018; Pieters \& Wedel, 2004; Wilson \& Casper, 2016;). Accordingly, Kaspar et al. (2019) study investigated whether demographic 
targeting attracts visual attention and examine whether it also affects brand attitude and website evaluation. The outcome indicated that demographic targeting could have moderate- to big-sized effects on so many eye movement parameters" at the event consumers are in a" free-viewing mode". The authors concluded that attention for individually applicable advertisement could be strong. In a similarly, Costa et al. (2019) investigated "driver's visual attention was assessed in a realistic driving setting for six categories of public space advertising. Thus, vendor signs, billboards, movable display boards, single and multiple commercial directional signs, and gas price LED displays". The findings revealed that fixation proportion was profoundly influenced by sign category, allowance from the road and numeral characteristics. While, Boronczyk et al. (2018) examined the impact of "exposing-related and consumer-related" features on the return of "sponsorship investment" over their influence on consumers' attention for sponsor signage". The findings revealed that consumers' attention for sponsor signage is exaggerated by the signage colour of simultaneous sponsors, as well as consumers' brand acquaintance, and sport participation.

\section{Impact of strategic ambiguity tagline in advertisements}

Indisputably, tagline is utilised to institute "brand's identity", increase awareness of the brand, arouse curiosity, produce a preferred "image and sheltered a position in the markets place that enables the "company" to attain the strategic sales targets and match its strength with competitors (Michalik \& MichalskaSuchanek, 2016). However, previous studies have investigated the impact of strategic ambiguity tagline on consumers such as Dirwan et al. (2021) study discovered that taglines have a favourable and considerable impact on purchase decisions. This signifies that the theory under consideration has been accepted. This indicates that the tagline may influence purchasing decisions; the tagline slogan in a product advertisement can help customers remember the product brand offered in order to make purchasing decisions. In a similar study, Devarai and Shetty (2010) study on the impact of tagline on consumers in the non-alcoholic beverages segment. The study concluded that taglines that persisted over a longer period indicated significant brand awareness and brand memorability compared to the ones that change from time to time, indicating a low brand awareness. In addition, taglines work sublimely in the minds of consumers even the products are not their favourite brand.

Meanwhile, Cheema et al. (2016) study on "do taglines have a positive impact on building the brand perception? A case study on Kit Kat". The study focused on the relationship between tagline and brand image. The study indicated that taglines does not only have strong "impact on brand perception" but they also help in creating strong brand associations". Besides, Munthe and Lestari (2016) study investigated the impression of rhetorical devices in Wendy's taglines". In most cases words, phrases and polysemy are used to encode significant meaning or information about the brand and "fast food" brands utilised texts to appeal the" audiences". The study revealed that engagement of "rhetorical devices" in the "taglines" influences the audience and assonance is reflected as the highly "persuasive rhetorical device".

However, tagline or catchphrase has been used extensively by advertisers to increase advertising's capacity to fulfil its objectives and influence the perception and image the consumers holds about the brand by implanting the catchphrase into their memory through using words or statements from notable endorsers and prominent leaders (Dirwan et al., 2021; Juliana \& Arafah, 2018). Accordingly, the work of Juliana and Arafah (2018) investigated the multimodal analysis of advertising tagline. The authors highlighted that tagline is a means of attracting the consumer's attention to remember the brand with the catchphrase. Moreover, tagline enables creation of a novel image of the products or brand and facilitate a persuasive "effect that affects the audience behaviour". However, the study concluded that the use of multimodal elements in "Tolak Angin Sidomuncul" Ads are interrelated with each other to express the connotation and information that is purposeful towards attracting consumers' attention to the brand. Similarly, code mixing is a linguistic perspective that has been applied in tagline and used by advertiser to influence favourable outcomes in an advertisement. In Pareek and Kumar (2018) study on the language of brand taglines, a code mixing approach and to comprehend the connotation and connection of code-mixed language of taglines that is depicted as the mingling and inserting of two dissimilar linguistic elements from two diverse structural schemes. The authors concluded that advertisers incorporate "lexical words from English in Hindi newspapers" that has accomplished and attracted high respect globally because of the "linguistic flavour' in an advertisement". Meanwhile, Silveira et al. (2017) in an article "Yes They Can?" - An empirical study on the effect of slogans in 
brand awareness". The study concluded that the effect of slogans on brand awareness was not equal across all the brands studied and, in two of the brands analysed. In addition, a higher probability of higher brand awareness levels in the "correct slogan" and a positive association between slogans recall and brand awareness in two of the three brands.

The previous studies have advanced a useful insight and methods on strategic ambiguity and tagline which the study identified attitude towards tagline, perception towards tagline and brand motive using tagline (explanatory variable) as proximal determinants of its influence on consumer's attention (outcome variable). However, these elements will enable the study to understand the impact of strategic ambiguity tagline in billboard advertising on consumer's attention. Based on previous discussion about impact of strategic ambiguity and tagline the study asks the following questions, proposed a framework (Figure 1), and hypothesis.

\section{Research Questions}

RQ1 Will the attitudes of consumers exposed to strategic ambiguity tagline differ on their attention from those that were unexposed?

RQ2 Will perception of consumers exposed to strategic ambiguity tagline differ on their attention from those that were unexposed?

RQ3 Do brand motives in the use of strategic ambiguity tagline impact on consumer's attention?

$\mathbf{H}_{\mathbf{1}}$ Consumers exposed to strategic ambiguity tagline will elicit favourable attention to brand on billboard than those unexposed.

$\mathbf{H}_{\mathbf{2}}$ There is significant difference between attitudes to tagline, perception to taglines and brand motives of consumers exposed to strategic ambiguity tagline on their attention from those that were unexposed.

\section{METHODS}

\section{Design and Participants}

Toward testing the hypothesis and addressing the research question, we designed an online-randomised post-test-only control group with between-subject experiment. The explanatory variable treatment levels utilised are (attitudes towards tagline, perception towards tagline, and brand motives using tagline). A total of 240 adult participants (Mage $=20$ ) were recruited from various continents (Asia, Africa, Europe, South America, North America, and Oceania) online platform users such as Wechat, Whatsapp, Weibo, QQ, Facebook, and Linkedin different countries and occupations with a (Mage $=20)$. The participants involved, $80 \%$ were male $(\mathrm{N}$ = 192), and 30\% were Africa ( $N=72$ ). In addition, $45 \%$ of participants were between the age bracket of (31-40), $(\mathrm{N}=108)$, and $90 \%$ of the participants $(\mathrm{N}=216)$ indicated that they have been exposed to tagline on billboard advertisement before.

\section{Procedures}

An online experiment was conducted through a google form. A consent to participate in an online experiment were sent to participants recruited through a non-probability sampling procedure on Wechat, Whatsapp, Weibo, QQ, Facebook, and Linkedin users requesting their consent to participate in an online experiment. After securing their consent, 300 different question link were sent to four groups that were randomised (three groups in the treatment level and one control group) after scheduling time and date of the experiment. The researcher selected 15 strategic ambiguity tagline and figure of speech ads from various old and current advertisements for pilot test with 30 students to check the method and instruments for the study and the pilot test yielded a significant result towards the methods and instruments designed for the study.

Similarly, the participant was randomly assigned to three-treatment condition and control group. The experimental group were three treatments levels (attitude towards the tagline, perception towards the tagline and brand motives using tagline) to enable between subject design and measuring the mean difference of each explanatory variable. 30 strategic ambiguity tagline were used and was divided into 11, 11, and 8 respectively to each of the treatment levels. The attitude towards tagline treatment had a billboard 


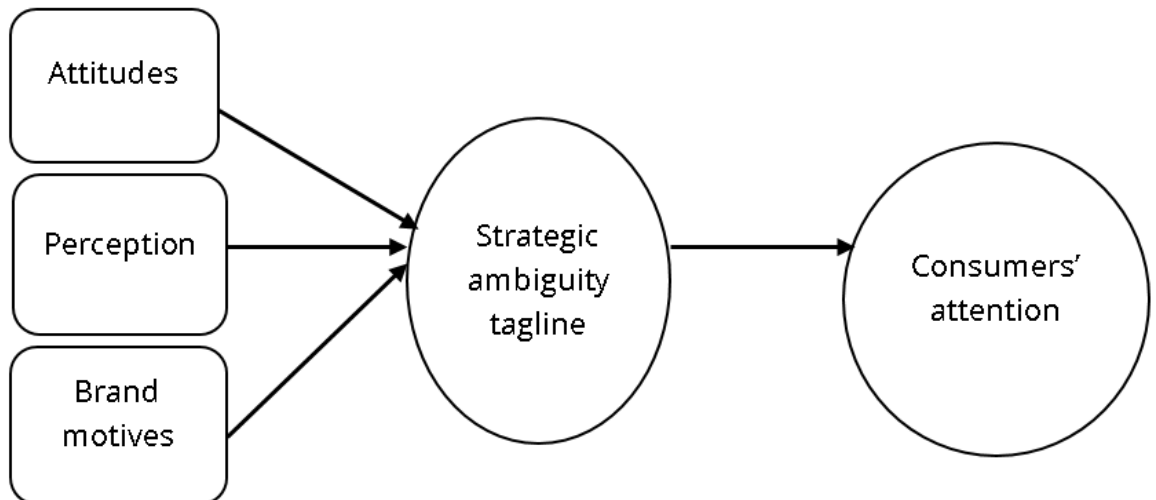

Figure 1. Proposed framework

advertisement with a tagline and the participants completed 17 questions; perception towards tagline treatment also had billboards with tagline and the participants completed 17 questions. Similarly, brand motives using tagline treatment had moderation/responsible billboards with a tagline and the participants completed 14 questions. In addition, the control group were not exposed to any tagline or billboard during the test period and the participant completed 36 questions from demographic to the section B, C, and D.

\section{Manipulations}

The attitude towards tagline epitomizes an assessment combination of thoughts and progresses "experienced" in related to a thing. Attitudes are the "evaluative" conclusions that combine and digest "cognitive" and "affective" responses (Ajzen \& Cote, 2008, p. 3; Albarracin \& Shavitt, 2018) were manipulated by presenting to the participants 11 different billboards advertisement taglines, which incorporated pause in between the target word, comprehension of the tagline and figures of speech that were drawn from old and new ads meant to determine the consumer attitude towards tagline. The group were coded as (B).

However, perception towards brand tagline is a consequence of the communication between the "perceived value" in terms of the structural elements in the design, usefulness, and psychological appeals, and properties of cognitive, affective and emotional that is embedded in a tagline (Aschemann-Witzel, 2018), were manipulated by sending to the participants 11 different billboards images with taglines embedded with different lettering case, typeface and figures of speech that were drawn from old and new ads meant to determine the consumer perception towards tagline. The group were coded as (C).

Similarly, brand motives using tagline are combination of catchphrase that gives idea of the product or services. It is created for marketing communication purposes which carries the entire benefits of the brand (Dhanyasree \& Kumar, 2018), were manipulated by presenting to the participants 8 different billboard advertisement images with moderation tagline that were drawn from old and new ads meant to determine the brand motives using tagline. The group were coded as (D).

In addition, the control group participants did not receive any strategic ambiguity tagline before completing the questions, which were meant to ascertain the effect of the treatment on the outcome variable (consumer's attention).

\section{MEASUREMENT}

The attitudes towards the tagline was measured with 11 item on a self-reported scale adopted from Song and Luximon (2019) and slightly modified to fit to our study. The participants responded to each item on scale from 1 (strongly disagreed) to 5 (strongly agreed) (Cronbach's a = .861, M =4.225, SD =1.01). Example of items included “This tagline makes me awake (They're G-r-r-reat) the tagline lettering case is compatible with the brand (They're G-r-r-reat) and the meaning of this tagline is familiar ("Just Do it").

Perception towards the tagline were measured with 11 items using semantic differential scale with bipolar adjective endpoints (pleasant/unpleasant, inviting/uninviting, incomprehensive/comprehensive) adopted from Henderson et al. (2004) and slightly modified to suit our study (Cronbach's a = .868, M = 3.808, SD =1.111). 
Example of items included "Now Everyone Can Fly (Given your experience on the tagline you saw, how you feel about the lettering case? "it's finger lickin' good" Given your experience on the tagline you saw, how would you rate the typeface? In addition, this tagline arouses my desire to eat "I'm Lovin' It" how you feel about the tagline?

The brand motives for using tagline were measured with 8 item of motivational dimension adopted from, Smith et al. (2006) and modified to 5 point Likert scale (agreed/disagreed) to suit the study. (Cronbach's a = $.864, \mathrm{M}=3.5042, \mathrm{SD}=1.251$ ). Example of items included "To improve the company's image," and "To make it appear they are concerned".

\section{RESULTS}

Prior to hypothesis testing and exploration of the research questions and checking the legitimacy of the strategic ambiguity tagline manipulation. The participant's response was assessed by asking them to indicate the extent of their agreement that strategic ambiguity tagline impact on their attention through a three treatment conditions, thus attitude to tagline, perception to tagline and brand motives. An independent sample $t$ test indicated that 120 participants who received treatment condition $(M=125.300, S D=10.266)$ compared to the 120 participants in the control group $(M=117.142, S D=15.709)$ which demonstrated a significant difference in the score $\mathrm{t}(238)-4.762, \mathrm{P}<.001$. This confirmed that the treatment condition was successful. The means and standard deviations of the experimental conditions are presented in Table 1.

Table 1. Mean and standard deviation across the experimental conditions

\begin{tabular}{lcc}
\hline Items & Mean & SD \\
\hline Attitude to tagline & 4.6542 & .57236 \\
Perception to tagline & 4.2417 & .98096 \\
Brand motives using tagline & 4.3417 & .74312 \\
\hline
\end{tabular}

A one-way between-subjects ANOVA was conducted to determine the effect of strategic ambiguity tagline (attitude to tagline, perception to tagline and brand motive using tagline) on consumer's attention as the dependent variable. The results of the ANOVA indicated a significant effect of strategic ambiguity tagline (attitude to tagline, perception to tagline and brand motive using tagline) on consumer's attention at $p<.05$ level across the three levels of conditions; $F(3,236)=7.49, p<.001$. The result in Table 2 supported the $H_{1}$, which explored that consumers exposed to strategic ambiguity tagline will elicit favourable attention to brand on billboard than those unexposed.

Table 2. Strategic ambiguity tagline and consumer's attention

\begin{tabular}{lccccc}
\hline Source & $\mathrm{df}$ & S.squares & Mean square & $\mathrm{F}$ & Sig. \\
\hline Between groups & 3 & 3993.504 & 1331.168 & 7.496 & .000 \\
Within groups & 236 & 41907.792 & 177.575 & & \\
Total & 239 & 45901.296 & & & \\
\hline
\end{tabular}

$\mathrm{H}_{2}$ explores the difference between attitudes to tagline, perception to taglines, and brand motives to consumers exposed to strategic ambiguity tagline on their attention from those that were unexposed. However, toward ascertaining the significant effect or difference among the treatment levels, a Dunnett's post hoc comparison test was conducted. The test analysis (Table 3 ) revealed that the mean score for attitude to tagline $(n=40, M=125.30, S D=10.353)$, perception to tagline $(n=40, M=125.30, S D=10.353)$ and brand motive using tagline $(n=40, M=125.30, S D=10.353$ ) were significantly different compared to the control group ( $n=120, M=117.142, S D=15.709$ ). Inclusively, these outcomes suggest that strategic ambiguity tagline impact on consumer's attention. Remarkably, this result suggests that when consumers are exposed to strategic ambiguity tagline on the billboard advertisement it will draw their attention to the brand in question, which invokes a thoughtful process and favourable behaviour like brand likening, purchase intention and loyalty. 
From Table 3, the following pair were found to be significantly different at .05 level of significance: * Attitude vs. control group, * perception vs. control group, and * brand motive vs. control group. However, the result supports the $\mathrm{H}_{2}$, that there is significant difference between attitudes to tagline, perception to taglines and brand motives of consumers exposed to strategic ambiguity tagline on their attention from those that were unexposed. Accordingly, Mantonakis (2012) mentioned taglines are utilized as a major marketing communication tool that communicates the proposition, which facilitate in reinforcing consumer memory and attention to the brand.

Table 3. Dunnett's post hoc comparison test for treatment levels and control group

\begin{tabular}{lcc}
\hline Groups (I-J) & Means difference (I-J) & Sign val(p) \\
\hline Attitude vs. control group & $8.15833^{*}$ & .003 \\
Perception vs. control group & $8.15833^{*}$ & .003 \\
Brand motive vs. control group & $8.15833^{*}$ & .003 \\
\hline
\end{tabular}

Note: * indicate significant difference

\section{DISCUSSION}

A great number of previous studies has investigated the influence of advertisement taglines on consumers in general. However, in spite of the numerous evidence little is known on the impact of strategic ambiguity tagline in billboard advertisement and how strategic ambiguity tagline influences consumer's attention. The study aimed at examining impact of strategic ambiguity tagline usage in billboard advertising, and how strategic ambiguity taglines influences consumer's attention.

We experimented on impact of strategic ambiguity tagline on billboard advertisement on consumers' attention, whereby three-treatment condition (attitude towards tagline, perception towards tagline and brand motive using tagline) were presented to participants against a control group in between subject design experiment. The result indicated that strategic ambiguity tagline had a significant impact on consumer's attention. The findings are consistent with previous research on the impact of tagline on brand image and consumers (Alissa, 2018; Do, 2019; Karim, 2019; Silveira et al., 2017).

Evidently, tagline-lettering case (uppercase vs. lowercase) arouses certain kind of feelings when used in an advertisement, which draws people's attention to the brand or context. The advertising tagline plays a fundamental role in advertisements towards communicating the detailed features of any given brand, product or services. Ideally, attitude towards tagline were significant over its impact on consumers' attention and we discovered that tagline lettering case aroused behavioural changes that is favourable in most cases. This finding extends the work of Song and Luximon (2019) study on "design for sustainability: The effect of lettering case on environmental concern from a green advertising perspective".

Remarkably, typeface is one of the most fundamental visual elements used in marketing communication tools towards apprehending consumer's attention to the brand and it is used in creating impressions that enables the brand to be seen in a positive point. However, perception towards tagline had a significant impact on consumer's attention and we discovered that typeface is fundamental to strategic ambiguity tagline liking and memorability. The finding further extends the study of Henderson et al. (2004) on "impression management using typeface design". In addition, perception determines how we see an object or feel about sets of stimulus in ads, which determine consumers' response to it, either favourable or unfavourable.

Similarly, advertisers in their eminent thoughts design tagline that will achieve multiple purposes for the brand and that remains a formidable fact that always guide their operations. Indeed, brand motive using strategic ambiguity tagline significantly influenced consumers' attention and the study revealed that advertisers use tagline to create good image, to communicate their brand, to show as if they really care about the consumer and to increase sales. The outcome extends the Smith et al. (2006) study on "are drink responsibly" alcohol campaigns strategically ambiguous? The findings provided an outstanding evidence on the impact of strategic ambiguity tagline on consumer's attention. Ideally, attitude towards tagline, perception towards tagline and brand motives using tagline positively influenced consumer's attention, which demonstrates that tagline is a means of attracting the consumer's attention to the brand with the catchphrase. 
Additionally, tagline enables creation of a novel image of the products or brand and facilitate a persuasive "effect that affects the audience behaviour". The practical implication and insights of the study findings will enable the advertisers and professionals to understand how to effectively create a tagline that is all-inclusive in terms of its ambiguity towards achieving multiple goals for the organisation.

The results offered useful insights about strategic ambiguity tagline and the empirical demonstration and procedures of this study shows that ambiguity tagline has the tendency of invoking multiple interpretation across multiple individuals towards achieving multiple goals for the organisation. Our data indicated that consumers exposed to strategic ambiguity tagline elicited favourable attention to brand on billboard than those unexposed. This supports postulation of Eisenberg (1984) that strategic ambiguity offers an opportunity to be "multiple personal, relational, political factors" and advertising that prime a context to accomplish with certain extent of ambiguity in the communications process, which increases the ability to attain goals, and serves four purposes towards promotion of unified diversity, preserves privilege positions, deniable and facilitate organisational change.

In general, advertisers and organisation can achieving multiple goals through creative usage of strategic ambiguity tagline as discursive resources that invokes multiple interpretation across multiple consumers, to attract, and sustain their attention to the brand. However, further scholarly research can focus on overall role of strategic ambiguity on purchase decision. In conclusion, this study contributes to the impact of strategic ambiguity tagline in billboard advertisement on consumer's attention. There was a growing controversy about ambiguity across different communication and other fields on how ambiguity creates lack of clarity and impediments in a communication process, which brought about discursive resources indicating that organisation communication with unclear symbols, slogans, taglines, and logo and still achieve purpose.

The study encountered several limitations; firstly, there were limited literature that specifically studied strategic ambiguity tagline in billboard advertising, which hindered the anticipated speed we scheduled on the study. Secondly, getting a suitable sample for this study posed a serious challenge to the study because of the coverage of the sample recruitment. However, future studies should limit their participant recruitment to a manageable location.

Author contributions: All authors were involved in concept, design, collection of data, interpretation, writing, and critically revising the article. All authors approve final version of the article.

Funding: The authors received no financial support for the research and/or authorship of this article.

Declaration of interest: Authors declare no competing interest.

Data availability: Data generated or analysed during this study are available from the authors on request.

\section{REFERENCES}

Aggerholm, H. K., Asmuß, B., \& Thomsen, C. (2012). The role of recontextualization in the multivocal, ambiguous process of strategizing. Journal of Management Inquiry, 21(4), 413-428. https://doi.org/10.1177/1056492611430852

Ajzen, I., \& Cote, N. G. (2008). Attitudes and the prediction of behaviour. In W. D. Crano \& R. Prislin (Eds.). Attitudes and attitude change (pp. 289-311). Psychology Press. https://perpus.univpancasila.ac.id

Albarracin, D., \& Shavitt, S. (2018). Attitudes and attitude change. Annual Review of Psychology, 69, $299-327$. https://doi.org/10.1146/annurev-psych-122216-011911

Asako, Y. (2019). Strategic ambiguity with probabilistic voting. Journal of Theoretical Politics, 31(4), 626-641. https://doi.org/10.1177/0951629819875516

Aschemann-Witzel, J. (2018). Consumer perception and preference for suboptimal food under the emerging practice of expiration date based pricing in supermarkets. Food Quality and Preference, 63, 119-128. https://doi.org/10.1016/j.foodqual.2017.08.007

Atkin, J. L., Mccardle, M., \& Newell, S. J. (2008). The role of advertiser motives in consumer evaluations of 'responsibility' messages from the alcohol industry, Journal of Marketing Communications, 14(4), 315-335. https://doi.org/10.1080/13527260802141447

Boronczyk, F., Rumpf, C., \& Breuer, C. (2018). Determinants of viewer attention in concurrent event sponsorship. International Journal of Sports Marketing and Sponsorship, 19(1), 11-24. https://doi.org/10.1108/IJSMS-09-2016-0063 
Botti, A., \& Monda, A. (2019). Goal ambiguity in public organizations: A systematic literature. International Journal of Business and Management, 14(7), 137-148. https://doi.org/10.5539/ijbm.v14n7p137

Boxman-Shabtai, L. (2020). Meaning multiplicity across communication subfields: Bridging the gaps. Journal of Communication, 70(3), 401-423. https://doi.org/10.1093/joc/jqaa008

Cappelen, S. M., \& Pedersen, J. S. (2021). Inventing culinary heritage through strategic historical ambiguity. Organization Studies, 42(2), 223-243. https://doi.org/10.1177/0170840620918382

Chatterjee, J. (2019). An analysis of consumers' perception towards rebranding: A study of hero MotoCorp. Journal of Modern Accounting and Auditing, 15(4), 210-219. https://doi.org/10.17265/15486583/2019.04.004

Cheema, F.-E. A., Rehman, S., Zia, S. \& Rehman, M.-U. (2016). Do taglines have a positive impact on building the brand perception? A case study on Kit Kat. IBT Journal of Business Studies, 12(1), 52-64. https://doi.org/10.46745/ilma.jbs.2016.12.01.05

Chetia, B. (2015). Rhetorical devices in English advertisement texts in India: A descriptive study. International Journal of Social Science and Humanity, 5(11), 980-984. https://doi.org/10.7763/ijssh.2015.v5.591

Costa, M., Bonetti, L., Vignali, V., Bichicchi, A., Lantieri, C., \& Simone, A. (2019). Driver's visual attention to different categories of roadside advertising signs. Applied Ergonomics, 78, 127-136. https://doi.org/10.1016/j.apergo.2019.03.001

Cranor, L. F., Habib, H., Zou, Y., Acquisti, A., Reidenberg, J., Sadeh, N., \& Schaub, F. (2020). Design and evaluation of a usable icon and tagline to signal an opt-out of the sale of personal information as required by CCPA. https://cups.cs.cmu.edu/pubs/CCPA2020Feb04.pdf

Devarai, K., \& Shetty, D. (2010). A study on the impact of taglines on consumers in the non-alcoholic beverages $\begin{array}{llll}\text { segment. SFIMAR Research } & \text { 4(10), }\end{array}$ http://www.sfimarresearchreview.org/index.php/srr/article/view/109215

Dhanyasree, V. K., \& Kumar, J. S. (2018). Importance of taglines in service branding (with special attention to banking sector). International Journal of Marketing and Technology, 8(7), 1-11.

Dimofte, C. V., \& Yalch, R. F. (2007). Consumer response to polysemous brand slogans. Journal of Consumer Research, 33(4), 515-522. https://doi.org/10.1086/510225

Dirwan, D., Themba, O. S., \& Latief, F. (2021). Aspect purchasing decisions at consumers lazada: Trust, price, tagline. Journal Economic Resource, 3(2), 86-93.

Do, T. (2019). The impact of tagline on brand image: A consumer experiment with a handmade locally brand. [Master Thesis, Hanken School of Economics].

Eisenberg, E. M. (1984). Ambiguity as strategy in organizational communication. Communication Monographs, 51(3), 227-242. https://doi.org/10.1080/03637758409390197

Fitts, J. K. (2010). Strategic ambiguity: The effects of viewing ambiguous advertisements on college students [Doctoral dissertation, Washington State University].

Fløttum, K. (2010). EU discourse: Polyphony and unclearness. Journal of Pragmatics, 42(4), 990-999. https://doi.org/10.1016/j.pragma.2009.08.014

Gupta, R. K., Khan, D., \& Ghosh, P. (2020). A study on the customers' perception of different children's health drinks. South Asian Journal of Marketing \& Management Research, 10(9), 29-39. https://doi.org/10.5958/2249-877X.2020.00063.6

Han, K. W., \& Choi, H.-L. (2018). Use of ambiguity in advertising creativity: A cross-cultural perspective. Indian Journal of Science and Technology 8(26). https://doi.org/10.17485/ijst/2015/v8i26/87112

Heberle, A., \& Gierl, H. (2020). When less is more: There must be a comprehensible reason for using incompleteness in advertisements to improve brand attitude. Journal of Research and Management, 42(3), 8-36. https://doi.org/10.15358/0344-1369-2020-3-8

Hoffjann, O. (2021). Between strategic clarity and strategic ambiguity-oscillating strategic communication. Corporate Communications: An International Journal. https://doi.org/10.1108/CCIJ-03-2021-0037

Hussain, J., \& Nizamani, R. K. (2011). Factors affecting consumer attention in billboards advertising. South Asian Journal of Management Sciences, 5(2), 60-64. http://sajms.iurc.edu.pk/issues/2011b/Fall2011V5N2P3.pdf

Ishchuk, N., \& Svirhun, A. (2020). Linguistic aspects of advertising slogans. https://r.donnu.edu.ua

Johansen, W. (2018). Strategic ambiguity. In R. Heath \& W. Johansen (Eds.), The international encyclopaedia of strategic communication. Wiley \& Son. https://doi.org/10.1002/9781119010722.iesc0170 
Jouttijärvi, S. (2019). The role of creative design in capturing consumer attention with effective banner advertising: An eye tracking approach [Master thesis, LUT University].

Juliana, J., \& Arafah, S. (2018). The multimodal analysis of advertising tagline" tolak angin sidomuncul" through systemic functional linguistics approach. Journal MELT (Medium for English Language Teaching), 3(2), 127137.

Kaspar, K., Weber, S. L., \& Wilbers, A. K. (2019). Personally relevant online advertisements: Effects of demographic targeting on visual attention and brand evaluation. PLOS One, 14(2), e0212419. https://doi.org/10.1371/journal.pone.0212419

Khan, K., Hussainy, S. K., Khan, A., \& Khan, H. (2016). Billboard advertising and customer attention: A Pakistani perspective. International Journal of Scientific and Research Publications, 6(3), 502-506.

Khaola, P. P., Potiane, B., \& Mokhethi, M. (2014). Environmental concern, attitude towards green products and green purchase intentions of consumers in Lesotho. Ethiopian Journal of Environmental Studies and Management, 7(4), 361-370. https://doi.org/10.4314/ejesm.v7i4.3

Lagerwerf, L. (2002). Deliberate ambiguity in slogans: Recognition and appreciation. Document Design, 3(3), 244-260. https://doi.org/10.1075/dd.3.3.07lag

Leitch, S., \& Davenport, S. (2003). Strategic ambiguity in communicating public sector change. Journal of Communication Management, 7(2), 129-139. https://doi.org/10.1108/13632540310807340

Lu, D., Neves, L., Carvalho, V., Zhang, N., \& Ji, H. (2018). Visual attention model for name tagging in multimodal social media. In Proceedings of the 56th Annual Meeting of the Association for Computational Linguistics (Volume 1: Long Papers), 1990-1999. https://doi.org/10.18653/v1/p18-1185

Mantonakis, A. (2012). A brief pause between a tagline and brand increases brand name recognition and preference. Applied Cognitive Psychology, 26(1), 61-69. https://doi.org/10.1002/acp.1797

Martin, M., \& Pajouh, M. S. (2019). Does strategic ambiguity have a place in the WTO dispute settlement understanding? US-China Law Review, 16(5), 215-222. https://doi.org/10.17265/1548-6605/2019.05.004

Michalik, U., \& Michalska-Suchanek, M. (2016). The persuasive function of rhetoric in advertising slogans. Journal of Accounting and Management, 6(1), 45-58. https://hrcak.srce.hr/162950

Miller, D. W., \& Toman, M. (2016). An analysis of rhetorical figures and other linguistic devices in corporation brand slogans. Journal of Marketing Communications, 22(5), 474-493. https://doi.org/10.1080/13527266.2014.917331

Munthe, A. M., \& Lestari, R. (2016). The impression of rhetorical devices in Wendy's taglines. Journal of Language and Literature, 16(2), 165-177. https://doi.org/10.24071/joll.2016.160207

Mykola, I., Vadym, A., Lokutova, O., Anatoliy, P., \& Romaniuk, I. (2020). Ways to develop brands and PR management of tourism enterprises with a focus on national markets. International Journal of Management, 11(5), 778-787.

Nasr, M. (2020). Strategic ambiguity and motivated reasoning: How voters' affective predispositions affect their reaction to party ambiguity. SSRN Electronic Journal. https://doi.org/10.2139/ssrn.3641563

Nayeem, T., Murshed, F., \& Dwivedi, A. (2019). Brand experience and brand attitude: Examining a credibilitybased mechanism. Marketing Intelligence \& Planning, 37(7), 821-836. https://doi.org/10.1108/MIP-112018-0544

Pareek, P., \& Kumar, V. V. R. (2018). An empirical study of the language of brand taglines: A code mixing approach. International Journal of Indian Culture and Business Management, 17(1), 109. https://doi.org/10.1504/ijicbm.2018.10013271

Parks, M. R. (1981). Ideology in interpersonal communication: Off the couch and into the World. Annals of the International Communication Association, 5(1), 79-107. https://doi.org/10.1080/23808985.1981.11923840

Patel, M. R., \& Bhatt, M. K. (2018). A study to know impact of outdoor advertising on customer purchase decision. SEMCOM Management \& Technology Review, 6(1), 113-117.

Penta, S. M. (2018). 30th anniversary "Just Do It". http://shanapenta.com/wp-content/uploads/2020/03/NIKECase-Study

Penz, E., \& Polsa, P. (2018). How do companies reduce their carbon footprint and how do they communicate these measures to stakeholders? Journal of Cleaner Production, 195, 1125-1138. https://doi.org/10.1016/j.jclepro.2018.05.263

Pieters, R., \& Wedel, M. (2004). Attention capture and transfer in advertising: Brand, pictorial, and text-size effects. Journal of Marketing, 68(2), 36-50. https://doi.org/10.1509/jmkg.68.2.36.27794 
Pietsch, K. (2021). Ambiguous environmental advertising-how brand advertising and consumers frame Rügenwalder Mühle's products [Master thesis, Swedish University of Agricultural Sciences]. https://stud.epsilon.slu.se

Reimer, C. B., \& Schubert, T. (2020). Visual and central attention share a capacity limitation when the demands for serial item selection in visual search are high. Attention, Perception, \& Psychophysics, 82(2), 715-728. https://doi.org/10.3758/s13414-019-01903-4

Richard-Bollans, A., Gómez Álvarez, L., \& Cohn, A. G. (2020). Modelling the polysemy of spatial prepositions in referring expressions. In Proceedings of the Seventeenth International Conference on Principles of Knowledge Representation and Reasoning. https://doi.org/10.24963/kr.2020/72

Rolin, C. O., \& Karahan, S. (2020). Effective communication. https://sites.wp.odu.edu/chrisrolinhpe469/wpcontent/uploads/sites/23831/2021/02/C.Rolin_.pdf

Schäfer, C. A. (2020). Everything has an end, only the sausage has two: Profit \& purpose: The case of Rügenwalder Mühle [Master thesis, the Universidade Católica Portuguesa]. https://repositorio.ucp.pt/bitstream/10400.14/31174/1/152118090_Carolin\%20Andrea\%20Sch\%C3\%A4 fer_DPDFA.pdf

Septianto, F., Chiew, T. M., \& Thai, N. T. (2020). The congruence effect between product emotional appeal and country-based emotion: The moderating role of country-of-origin. Journal of Retailing and Consumer Services, 52, 101916. https://doi.org/10.1016/j.jretconser.2019.101916

Shahid, S. E., \& Ashfaq, A. (2021). Coca-Cola and PepsiCo advertising in Pakistan: Changing trends of cultural values manifested in television commercials. Journal of the Research Society of Pakistan, 58(2), 270-281.

Silveira,P., Galvao, S., \& Penteado, G.(2017).“'Yes they can?" -An empirical study on the effect of slogans in brand awareness. In C. Ignatescu, A. Sandu, \& T. Ciulei (Eds.), Rethinking social action. Core values in practice (pp. 820-831). LUMEN Proceedings. https://doi.org/10.18662/lumproc.rsacvp2017.75

Singh, S. (2006). Impact of color on marketing. Management Decision, 44(6), 783-789. https://doi.org/10.1108/00251740610673332

Smith, S. W., Atkin, C. K., \& Roznowski, J. (2006). Are "Drink Responsibly" alcohol campaigns strategically ambiguous? Health Communication, 20(1), 1-11. https://doi.org/10.1207/s15327027hc2001_1

Song, Y., \& Luximon, Y. (2019). Design for sustainability: The effect of lettering case on environmental concern from a green advertising perspective. Sustainability, 11(5), 1333. https://doi.org/10.3390/su11051333

Stacho, Z., Stachová, K., Papula, J., Papulová, Z., \& Kohnová, L. (2019). Effective communication in organisations increases their competitiveness. Polish Journal of Management Studies, 19(1), 391-403. https://doi.org/10.17512/pjms.2019.19.1.30

Sumelius, J., Smale, A., \& Yamao, S. (2020). Mixed signals: Employee reactions to talent status communication amidst strategic ambiguity. The International Journal of Human Resource Management, 31(4), 511-538. https://doi.org/10.1080/09585192.2018.1500388

Sundar, A., \& Cao, E. S. (2018). Punishing politeness: The role of language in promoting brand trust. Journal of Business Ethics, 164(1), 39-60. https://doi.org/10.1007/s10551-018-4060-6

Supphellen, M., \& Nygaardsvik, I. (2002). Testing country brand slogans: Conceptual development and empirical illustration of a simple normative model. Journal of Brand Management, 9(4), 385-395. https://doi.org/10.1057/palgrave.bm.2540085

Suseno, B., \& Hidayat, A. (2021). Local pride movement as a local sneaker branding strategy. Journal of Indonesian Applied Economics, 9(2), 48-59. https://doi.org/10.21776/ub.jiae.2021.009.02.6

Syahruddin, \& Karim, A. (2019). The effect of "Axis Hits Bonus" version tagline advertising and Aambassador brand against axis cards awareness. In Proceedings of the First International Conference on Materials Engineering and Management - Management Section. https://doi.org/10.2991/icmemm-18.2019.13

Teletova, S., \& Letunovska, N. (2019). Use of language games in advertising texts as a creative approach in advertising management. Periodicals of Engineering and Natural Sciences, 7(2), 458-465. Error! Hyperlink reference not valid.

Thapa, M. (2021). Perception and preference towards online education in Nepali academic setting. Preprints, 2021, 2021010482. https://doi.org/10.20944/preprints202101.0482.v1

Tur, A. P. A., \& Pratishara, G. (2018). Tagline branding: Trading the products or cultural identities? In Proceedings of the International Conference of Communication Science Research. https://doi.org/10.2991/iccsr-18.2018.82 
Wang, B., Wang, C., Zhang, Q., Su, Y., Wang, Y., \& Xu, Y. (2020). Cross-lingual image caption generation based on visual attention model. IEEE Access, 8, 104543-104554. https://doi.org/10.1109/access.2020.2999568

Wang, X., \& Yang, Z. (2010). The effect of brand credibility on consumers' brand purchase intention in emerging economies: The moderating role of brand awareness and brand image. Journal of Global Marketing, 23(3), 177-188. https://doi.org/10.1080/08911762.2010.487419

Wilson, R. T., \& Casper, J. (2016). The role of location and visual saliency in capturing attention to outdoor advertising: how location attributes increase the likelihood for a driver to notice a billboard ad. Journal of Advertising Research, 56(3), 259-273. https://doi.org/10.2501/JAR-2016-020

Winstock, A. R., Holmes, J., Ferris, J. A., \& Davies, E. L. (2020). Perceptions of alcohol health warning labels in a large international cross-sectional survey of people who drink alcohol. Alcohol and Alcoholism, 55(3), 315322. https://doi.org/10.1093/alcalc/agz099

Woo Jun, J., \& Lee, H. (2007). Cultural differences in brand designs and tagline appeals. International Marketing Review, 24(4), 474-491. https://doi.org/10.1108/02651330710761035

Wright, A. M. (2019). Let's be perfectly clear about ambiguity: Exploring instructor use of strategic ambiguity to enhance student work and learning outcomes [PhD thesis, Illinois State University]. https://ir.library.illinoisstate.edu/cgi/viewcontent.cgi?article=2148\&context=etd

Zehra, S., \& Minton, E. (2020). Should businesses use religious cues in advertising? A comparison of consumer perceptions across Christianity and Islam. International Journal of Consumer Studies, 44(5), 393-406. https://doi.org/10.1111/ijcs.12512

Zhou, L. (2021). The application of lexical ambiguity in advertising English. Journal of Frontiers of Society, Science and Technology, 1(7), 65-68.

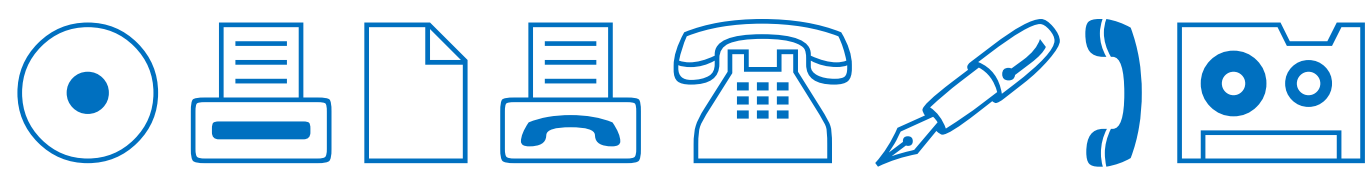

